\title{
Development of a procrastination scale in Spanish and measurement of students' procrastination tendencies
}

\author{
José Luis González-Geraldo ${ }^{1}$, Fuensanta Monroy Hernández ${ }^{2}$ \\ ${ }^{1}$ University of Castilla-La Mancha, Spain, ${ }^{2}$ University of Murcia, Spain.
}

\begin{abstract}
Academic procrastination (students' tendency to postpone and/or avoid an academic task) is a widely extended phenomenon in education, especially among university students. However, there is still little research on this topic and no single validated and widely accepted instrument to measure procrastination levels at university level in Spain has been developed yet. This study aimed to cover this gap and develop a procrastionation scale adapted from two existing instruments and to measure the procrastination tendencies of a sample of 529 students from two different universities. The results showed that the Escala de Procrastinación Académica en español (EPAE) has excellent reliability $(\alpha=.929)$. In addition, over $17 \%$ of the sample reported high procrastination levels. Although further research is needed, this preliminary study sheds light on this topic and contributes to the development of a measurement instrument that may be used to monitor student learning and identify, among other issues, students at risk of dropout.
\end{abstract}

Keywords: academic procrastination; university student; validation; higher education 


\section{Introduction}

Early studies on procrastination as a phenomenon with negative connotations date back to the 1980s, and describe it as "the act of needlessly delaying tasks to the point of experiencing subjective discomfort" (Solomon \& Rothblum, 1984, p. 503), while others refer to it as the "lack or absence of self-regulated performance [...], a tendency to [deliberately] put off or completely avoid an activity under one's control" (Tuckman, 1991, p. 474). More recent study claim that "procrastination is not an irrational personality disorder; it is a logical, albeit potentially inefficient, behaviour driven by a reasoned comparison of perceived costs and benefits" (Zarick \& Stonebraker, 2009, p. 211). Individuals may procrastinate in all sorts of everyday activities, as well as in academic and professional context, for various reasons and not always with negative connotations, so this phenomenon is multifaceted.

Although procrastination has been subject of analysis for the past thirty years, research is still needed to fully understand this complex and multifactorial phenomenon, which is often confused with laziness or self-indulgence (Natividad Sánchez, 2014). Literature reviews on procrastination, although not all systematic in nature, reveal that the prevalence of procrastination is particularly high among university students (see Steel, 2007) and that a better understanding of this phenomenon may contribute, among other things, to reducing dropout rates (Garzón Umerenkova \& Gil Flores, 2007).

Steel's (2007) meta-analysis of procrastination's possible causes and effects showed that neuroticism, rebelliousness, and sensation seeking show only a weak connection to procrastination, while strong and consistent predictors of procrastination were task aversiveness, task delay, self-efficacy, impulsiveness, conscientiousness and its facets of self-control, distractibility, organization, and achievement motivation. Other studies have found that high levels of procrastination are related to poor academic performance (Steel, 2007; Tuckman, 1998; Zarick \& Stonebraker, 2009), fear of failure (Solomon \& Rothblum, 1984), increased levels of psychological distress, and a tendency to seek high but unrealistic aims (perfectionism) (Flett, Stainton, Hewitt, Sherry, \& Lay, 2012).

For the past decades instruments have been designed to measure procrastination in general terms and when undertaking academic tasks. Some of most widely used in the latter group are: Solomon and Rothblum's (1984) Procrastination Assessment Scale for Students (PASS), Busko's (1998) Procrastination Scale, and Tuckman's (1991) Procrastination Scale (TPS). In Spanish language some of the aforementioned scales have been adapted, such as Furlan, Heredia, Piemontesi, and Tuckman's (2012) adaptation of Tuckman's TPS to Argentinian students (ATPS), and Álvarez Blas' (2010) adaptation of Busko's Academic Procrastination Scale. There is, however, a lack of consensus as to what is the most appropriate instrument. 
In light of the association between procrastination and other variables, monitoring procrastination may become the focus of attention of academic authorities interested in assessing and understanding student learning and learning outcomes (process and results). Proper detection with reliable instruments ensures that procrastination is diagnosed, or even predicted, and its negative side effects are minimized with the help of intervention programmes. Thus, the aims of this study were: a) to develop and validate a scale to measure academic procrastination in Spanish by adapting two existing instruments and, $b$ ) to measure the procrastination tendencies of a sample of university students.

\section{Method}

\subsection{Participants}

Data were collected from 574 students (present in class at regular teaching hours) from year 1 and 3 from two Spanish universities, while 529 questionnaires turned out to be usable. Students were selected by non-probability sampling. Participation was voluntarily once students had been informed about the study objective and their rights in terms of confidentiality and anonymity of data. Tables 1 and 2 show descriptive data sorted by university, degree and gender.

Table 1. Distribution of the sample ( $n=529)$ by university and degree (academic year 20172018).

\begin{tabular}{|c|c|c|c|c|c|c|c|c|c|c|}
\hline \multicolumn{5}{|c|}{$\begin{array}{c}\text { University of Murcia (UM) } \\
\text { (n=354), FEM: } 80.2 \% \text {; MAL: } 19.8 \%\end{array}$} & \multicolumn{6}{|c|}{$\begin{array}{l}\text { University of Castilla-La Mancha (UCLM) } \\
\qquad(n=175), \text { FEM: } 60 \% \text {; MAL: } 30.9 \%\end{array}$} \\
\hline TEL & \multicolumn{2}{|c|}{$\mathrm{PE}$} & \multicolumn{2}{|c|}{$\mathrm{SE}$} & \multicolumn{2}{|c|}{ TEL } & \multicolumn{2}{|c|}{$\mathrm{PE}$} & \multicolumn{2}{|c|}{ SE } \\
\hline$\%$ & $\mathrm{n}$ & $\%$ & $\mathrm{n}$ & $\%$ & $\mathrm{n}$ & $\%$ & $\mathrm{n}$ & $\%$ & $\mathrm{n}$ & $\%$ \\
\hline 0 & 183 & 51.7 & 171 & 48.3 & 30 & 17.1 & 88 & 50.3 & 57 & 32.6 \\
\hline
\end{tabular}

Note. TEL: Telecommunications Engineering, PE: Primary Education, SE: Social Education; FEM: females, MAL: males

\subsection{Design and procedure}

This study implemented a survey design as researchers were interested in participants' opinions and perceptions about the extent to which they procrastinate in academic tasks. Administration time was approximately 22 minutes, took place in regular classrooms, and followed the same administration procedure previously agreed by the researchers. 


\subsection{Data collection}

An ad hoc scale was designed adapting two existing instruments as a basis, namely Tuckman's (1991) 35-item Procrastination Scale and Busko's (1998) 28-item "Student Procrastination Scale" in order to measures Spanish university students' levels of academic procrastination. The reason for choosing these two scales was that they have both been widely used in previous studies. The resulting scale (Escala de Procrastinación Académica en español (EPAE) / Academic Procrastination Scale in Spanish) had 33 items and was made up of the 16 items specifically focused on academic procrastination in Busko's scale, 16 selected from the Tuckman's scale, and an additional item derived from splitting one of Tuckman's items into two for the purpose of clarity. This additional item was, however, later removed because of a low loading (below .3).

Following prior studies the final version of the questionnaire was made up of two dimensions: a) 17 procrastination items (12 from Tuckman and 5 from Busko), and b) 15 non-procrastination items (4 from Tuckman and 11 from Busko). The final selection of items was done in terms of relevance to the aim of this study, namely procrastination in academic tasks. Examples of items were "When I have a deadline, I wait till the last minute" (procrastination dimension) and "I generally prepare well in advance for exams" (non-procrastination dimension). When completing the scale participants had to chose between four options in terms of whether each scale item described them when facing acadmic tasks (1-This is not me at all, 2-This is usually not me, 3-This is usually me, 4-This is definitely me). As the participants were Spanish speakers and the scales were originally written in English, the researchers implemented the back-translation method as one of the recommended techniques (Epstein, Miyuki Santo, \& Guillemin, 2015).

\subsection{Data analysis}

In order to validate the academic procrastination scale designed in this study, an exploratory factor analysis (EFA) using Maximum Likelihood (ML) analysis with oblique rotation was performed using statistical programme SPSS version 24. In addition, Cronbach's alpha was used to calculate the internal consistency of the scale.

\section{Results and discussion}

\subsection{Structural validity}

Two EFA using Maximum Likelihood (ML) with oblique rotation were performed using the 33 items initially proposed by the researchers. The first EFA resulted in 7 factors but the second was forced to two factors in order to accommodate the two profiles (procrastination and non-procrastinator). Preliminary results showed that all items in the procrastinator dimension loaded as expected and had coefficients above .3. There non-procrastinator 
dimension showed some irregularities, namely item 1 ("I rarely put off until tomorrow what I can do today", Busko's item 15), item 6 ("Whenever I make a plan of action, I follow it", Tuckman's item 25), and item 19 ("Putting something off until tomorrow is not the way I do it", Tuckman's item 34) did not reach a coefficient of .3 in this dimension and had a negative loading above .3 in the procrastinator dimension. In addition, item 11 ("I always finish important jobs with time to spare", which is item 29 in Tuckman's scale) had a very load loading, so it was discarded and a new EFA with 31 items was performed (Table 2).

\subsection{Internal consistency}

Cronbach's alpha coefficients were calculated for each of the two scales (procrastination profiles) resulting from the forced EFA once the incongruent item (11) had been discarded. The results showed excellent reliability coefficient in the procrastinator dimension $(\alpha=$ .913 ) and good reliability coefficient in the non-procrastinator dimension $(\alpha=.841)$ following George and Mallery's (2003) rule of thumb for the acceptability of reliability coefficients (namely, >.9, excellent; >.8, good, >.7, acceptable; >.6, questionable; >.5, poor; and <.5, unacceptable). Similar to Tuckman (1998), reliability of the whole scale was calculated bearing the scale as unidimensional, which involved turning negative scale statements into positive. In this case, reliability was . 929, which is excellent.

\subsection{Procrastination tendencies of Education students}

Similar to Tuckman (1998), and taking the scale as unidimensional as described earlier, mean scores were calculated, so students were divided into three groups: a) those with mean score 1-2 (low tendency to procrastinate), b) those with mean score 2-3 (medium tendency to procrastinate), and c) those with mean score 3-4 (high tendency to procrastinate). As shown in Table 3, about $45 \%$ of students showed medium procrastination tendencies when accomplishing academic tasks, while over $17 \%$ turned out to be high procrastinators. 
Table 2. Factor structure of EPAE forced to two factors and without item 11.

\begin{tabular}{|c|c|c|}
\hline & Procrastinator & Non-procastinator \\
\hline Item 9 & ,813 & \\
\hline Item 5 & ,794 & \\
\hline Item 4 & ,781 & \\
\hline Item 12 & ,748 & \\
\hline Item 14 &, 710 & \\
\hline Item 15 & ,709 & \\
\hline Item 13 & 674 & \\
\hline Item 10 & ,673 & \\
\hline Item 21 & ,603 & \\
\hline Item 31 &, 573 & \\
\hline Item 24 & ,571 & \\
\hline Item 8 &, 515 & \\
\hline Item 23 & ,485 & \\
\hline Item 3 & ,443 & \\
\hline Item 18 & ,428 & \\
\hline Item 22 & ,421 & \\
\hline Item 19 &,- 379 & \\
\hline Item 1 &,- 366 & \\
\hline Item 7 & ,349 & \\
\hline Item 6 &,- 336 & \\
\hline Item 28 & & ,687 \\
\hline Item 30 & & ,667 \\
\hline Item 29 & & ,639 \\
\hline Item 26 & &, 552 \\
\hline Item 20 & &, 516 \\
\hline Item 25 & &, 506 \\
\hline Item 17 &,- 319 & ,430 \\
\hline Item 16 & & ,428 \\
\hline Item 27 & & ,405 \\
\hline Item 32 & &, 327 \\
\hline Item 2 & & ,312 \\
\hline
\end{tabular}

Extraction Method: Maximum Likelihood. Rotation Method: Oblimin with Kaiser Normalization. Items in gray are procrastination items. Items in italics are adapted from Busko (1998) and the remaining from Tuckman (1991).

Loadings below .3 were discarded. 
Table 3. Distribution of the sample $(n=529)$ by tendency to procrastinate

\begin{tabular}{ccccccc}
\hline & Low & \multicolumn{2}{c}{ Medium } & \multicolumn{2}{c}{ High } \\
\hline $\mathrm{n}$ & $\%$ & $\mathrm{n}$ & $\%$ & $\mathrm{n}$ & $\%$ \\
199 & 37.6 & 307 & 45.1 & 23 & 17.3 \\
\hline
\end{tabular}

\section{Conclusions}

This preliminary study developed a procrastination scale in Spanish language after adapting two existing and widely instruments in English. Factor analyses helped identify a dissonant item which was discarded, so the final version had 31 items. The new scale, Escala de Procrastinación Académica en español (EPAE) (Academic Procrastination Scale in Spanish) has an excellent reliability coefficient as shown in this study, and can safely be used to measure Spanish higher education students' procrastination tendencies.

This study also showed that over $17 \%$ of the sample may be described as high procrastinators, which could negatively influence their learning. Further analysis would be required on these students by collecting qualitative data in order to fully understand this phenomenon. In addition, further studies may wish to access students' academic record in order to compare grades and procrastination tendencies and identify any links that may support the literature. Moreover, a comparative analysis of procrastination tendencies of students in different academic years (i.e. freshmen and nearly graduates) may be worth doing.

Given the excellent inicial psychometric properties of the EPAE, it may be useful for monitoring students' learning, as high levels of procrastination are related to poor academic performance, as shown by previous studies (e.g., Steel, 2007; Tuckman, 1998; Zarick \& Stonebraker, 2009). Thus, academic authorities may decide to administer it to identify those students at risk and develop intervention programmes accordingly. This would, in turn, reduce university dropout rates and foster retention. Furthermore, the EPAE may be useful to Counseling and Psychological Services at universities in order to identify possible cases of anxiety at early stage. Finally, reducing procrastination levels among university students may decrease stress levels among students, as well as improve the quality of the teachinglearning process.

\section{References}

Álvarez Blas, O. R. (2010). Procrastinación general y académica en una muestra de estudiantes de secundaria de Lima metropolitana. Persona, 13, 159-177. 
Busko, D. A. (1998). Causes and consequences of perfectionism and procrastination: a structural equation model (Doctoral dissertation). Retrieved from http://citeseerx.ist.psu.edu/viewdoc/download?doi=10.1.1.456.4450\&rep=rep1\&type=p $\underline{\mathrm{df}}$

Epstein, J., Miyuki Santo, R., \& Guillemin, F. (2015). A review of guidelines for crosscultural adaptation of questionnaires could not bring out a consensus. Journal of Clinical Epidemiology, 68, 435-441.

Ferrari, J. R., Parker, J. T., \& Ware, C. B. ( 1992). Academic procrastination: Personality correlates with Myers-Briggs Types, self-efficacy, and academic locus of control. Journal of Social Behaviour and Personality, 7(3), 495-502.

Flett, G. L, Stainton, M., Hewitt, P. L., Sherry, S. B., y Lay, C. (2012). Procrastination automatic thoughts as a personality construct: An analysis of the Procrastinatory Cognitions Inventory. Journal of Rational-Emotive and Cognitive-Behavior Therapy, 30, 223-236.

Furlan, L. A., Heredia, D. E., Piemontesi, S. E., \& Tuckman, B. W. (2012). Análisis factorial confirmatorio de la adaptación argentina de la escala de procrastinación de Tuckman (ATPS). Perspectivas en Psicología, 9, 142-149.

Garzón Umerenkova, A., \& Gil Flores, J. (2017). El papel de la procrastinación académica como factor de la deserción universitaria. Revista Complutense de Educación, 28(1), 307-324.

George, D., \& Mallery, P. (2003). SPSS for Windows step by step: A simple guide and reference, 11.0 update ( $4^{\text {th }}$ ed). Boston, MA: Allyn and Bacon.

Natividad Sánchez, L. A. (2014). Análisis de la procrastinación en estudiantes universitarios. (Doctoral dissertation). Retrieved from http://mobiroderic.uv.es/bitstream/handle/10550/37168/Tesis\%20Luis\%20A.\%20Nativi dad.pdf?sequence $=1 \&$ isAllowed $=y$

Solomon, L. J., \& Rothblum, E. D. (1984). Academic procrastination: frequency and cognitive-behavioral correlates. Journal of Counseling Psychology, 31(4), 503-509.

Steel, P. (2007). The Nature of Procrastination: A Meta-Analytic and Theoretical Review of Quintessential Self-Regulatory Failure. Psychological Bulletin, 133(1), 65-94.

Tuckman, B. W. (1991). The development and concurrent validity of the Procrastination Scale. Educational and Psychological Measurement, 51, 473-480.

Zarick, L. M., \& Stonebraker, R. (2009). I'll do it tomorrow the logic of procrastination. College Teaching, 57(4), 211-215. 